\title{
Scheduling Strategies for the Thermal-hydro Coordination Based on the Large System Theory in Electricity Market
}

\author{
Jiang Dongrong \\ Department of Electrical Engineering, \\ Chongqing University of Technology, Chongqing 400050, China
}

\begin{abstract}
In the electricity market, the first problem considered by the power grid company is the safety and economy of power grid. So, the power grid company must not only ensure the power grid safety but also consider the effects of power transaction and the thermal-hydro coordination in the daily scheduling strategies. Thus, it is necessary to carry out the economic predicting dispatch between the competitive volumes and the contract volumes of the thermal power plants and hydropower plants. Aiming at this goal, in this paper the thermal-hydro coordination economical scheduling model is established for the next transaction day under the electricity market environment. At the same time, the decomposition method based on the large-scale system coordination theory is used to solve the economical model for the needing of real-time dispatching. And then, the simplify solving methods are used for the sub economical model of the thermal power plants and hydropower plants. At last, the IEEE 30 bus simulation proves these scheduling strategies are correct, simple and practical, credible and able to satisfy the daily economical scheduling demand for the large-scale power grid in the electricity market.
\end{abstract}

Keywords-Large-scale system coordination, Electricity market, Thermal-hydro coordination scheduling, Linear programming, DC power flow

\section{INTRODUCTION}

With the diversification of power supply and demand, and the development of electricity market, it will be difficult to keep up with the economic and social development to adopt the traditional operation control way for the power industry and only emphasize the safety and reliability of the system operation. The power system operation specialty is brought on for the balance between supply and demand of power system, the difficulty to store a great deal of electric energy, the intensiveness of funds and technology, the longer construction period and so on. On the ensuring of the power system safety and reliability, increasing the economic benefit of power system operation has become issues for electric power industry. Therefore, it becomes more and more important how to research, develop and realize the real-time integrated economic scheduling based on the operation rules of power system and the operation characteristics of market.

In current electricity market, the power company, the singular buyer representing for the users, has the core of its power dispatching, which is minimizing the purchase cost and protecting the benefit of power plants. Only in this way, the power system generation capacity adequacy can be ensured, power system can operate securely and the electricity market can develop steadily. The power plants in the power system include not only many thermal power plants, but also a large number of hydropower plants. Under the market environment, it is very important how to coordinate the thermal and hydropower plants scheduling and realize the energy-saving and emission reduction. Therefore, in economical dispatching, the coordinated constraints between the thermal power plants and the hydropower plants must be considered[1,2].

Before the electrical transaction, the power companies not only consider the power plants' competitive bidding spot price and volume, but also pay attention to the original purchase contract with the original power plants and the spinning reserve of power system. Therefore, it is necessary to coordinate the volumes among the contract bids and the competitive bids for the predicted generation volumes[3].

In electricity market, the coordination dispatching of thermal power plants and hydropower plants belongs to multi-objective, multi-stage non-linear optimization problem. It is very difficult to solve it directly. In real-time dispatching, calculation time must be very short. So, the core is searching the fast solving algorithm. In general, it is difficult for the classical optimization algorithm to resolve the hydro-thermal real-time coordination scheduling under the electricity market. Adopting the modern artificial intelligence algorithm can resolve the hydro-thermal realtime coordination scheduling efficiently, but the long calculation time can not meet the requirement of real-time scheduling[3]. In this paper, using the decomposition method based on the large-scale system coordination theory for the problem of hydro-thermal coordination scheduling, the difficult of optimization algorithm in the hydro-thermal system can be resolved efficiently.

\section{BUILDING THE MATHEMATICAL MODEL}

\section{A. Market assumption}

1) As possible as meeting the hydro power generation, decreasing the surplus water, adopting the contract way to the settlement of the hydro power pricing, no power limit, enough showing the policy of environment protection, energy-saving and emission reduction, only considering the thermal power purchasing cost among the ones of economic scheduling. 
2) Total dispatching generated energy of thermal power plants equals the total load demand minus total generated energy of hydro power plants.

3) Generated energy of thermal power plants includes contract volume and competitive volume. Contract price is settled with contract engagement. Competitive price is settled with the system marginal price for every period.

Because power grid company is the single buyer in the electricity market transaction, the demand elasticity is not considered. Market transaction is complete competition, no coordination, no market power between the market joiners, independence of each unit's generation in the whole power grid. The generation volume change of balance unit in power grid is very small for the other units. So the effects on the generation volume change of balance unit are not considered.

B. Building the objective function of hydro-thermal coordination dispatching in present electricity market

Under the front assumptions, the objective function is:

$$
\begin{aligned}
& F\left(P_{i}(t), P_{i}^{\prime}(t), U_{i}^{t}\right) \\
& =\min \sum_{t=1}^{T} \sum_{i=1}^{T}\left\{\left[C_{i} P_{i}(t)+C_{i t}^{\prime} P_{i}^{\prime}(t)\right] U_{i}^{t}+S_{i} U_{i}^{t}\left(1-U_{i}^{t-1}\right)\right\}
\end{aligned}
$$

Where: $F\left(P_{i}(t), P_{i}^{\prime}(t), U_{i}^{t}\right)$ is minimum payment of the power company, $(¥)$; $t$ is the bidding period $t$; $i$ is the thermal unit $i ; I$ is total number thermal unit in the power system; $U_{i}^{t}$ is commitment state ( 1 or 0 ) of unit $i$ in period $t$; $C_{i}$ is contract price of unit $i,(Y / \mathrm{MW}) ; C_{i t}{ }^{\prime}$ is predicted marginal cleaning price in period $t$, ( $Y / \mathrm{MW}$ ), no relation with the unit, so simplified as $C_{t}^{\prime} ; P_{i}(t)$ is contract volume of unit $i$ in period $t$, (MW); $P_{i}^{\prime}(t)$ is competitive bidding volume of unit $i$ in period $t(\mathrm{MW}) ; S_{i}$ is start up and stop cost of thermal unit $i$.

The constraints for the problem are: System power balance in period, Water volume balance, Unit generation limits, Minimum run-time and stop-time limits, Unit generation power up and down rate in one period and Safety constraints of power grid.

C. Simplifying the model

Evidently, the mathematic model described in Equation (1) is a nonlinear dynamic programming model containing the mixed-integral variables and constraints. It is difficult to solve this model directly. For the seeking process simply and practically, it is necessary to approximately simplify the model and constraints in certain scope. Presently, the total purchase cost of each power plant in China all includes the up-down cost. So, $S_{i}$ may be set as 0 . Based on efficiency priority rules, hydro power plants priority optimization, total load demand and executive contract volume condition, the unit commitment is determinate. So, assumption all the thermal unit generation, setting the variable of commitment state $U_{i t}$ as 1 . Then, the Equation (1) is simplified as:

$$
F\left(P_{i}(t), P_{i}^{\prime}(t)\right)=\min \sum_{t=1}^{T} \sum_{i=1}^{I}\left[C_{i} P_{i}(t)+C_{t}^{\prime} P_{i}^{\prime}(t)\right]
$$

\section{LARGE-SCALE SYSTEM COORDINATION DECOMPOSITION PROCEEDING}

Construction Lagrange function of objective function and the system power balance, spinning reserve constraints as follow:

$$
\begin{aligned}
& L(P, \lambda, \mu)= \\
& \sum_{t=1}^{T}\left[\sum_{i=1}^{I}\left(C_{i} P_{i}(t)+C_{t}^{\prime} P_{i}^{\prime}(t)\right)\right. \\
& \quad+\lambda(t)\left(P_{d}(t)+P_{L}(t)-\sum_{i=1}^{I}\left(P_{i}(t)+P_{i}^{\prime}(t)\right)-\sum_{j=1}^{J} P_{j}(t)\right) \\
& +\mu(t)\left(P_{d}(t)+P_{L}(t)+R^{t}-\sum_{i=1}^{I} \overline{P_{i \max }(t)}-\sum_{j=1}^{J} \overline{\left.P_{j \max }(t)\right)}\right]
\end{aligned}
$$

Where: $P_{L}(t)$ is total grid loss in period $t ; P_{j}(t)$ is generation power of hydro unit $j$ in period $t ; R^{t}$ is system spinning reserve demand in period $t ; \overline{P_{\text {max }}(t)}$ and $\overline{P_{j \max }(t)}$ is the power up limits of thermal unit $i$ and hydro unit $j$.

Assumption $P_{0}(t)$ is the operation start point, then construction the Taylor's series of Lagrange function and preserving the lonelier parts, so:

$$
L(P, \lambda, \mu)=L\left(P_{0}(t)+\Delta P, \lambda, \mu\right)
$$

$$
\begin{aligned}
=\sum_{t=1}^{T} \sum_{i=1}^{I}\left(C_{i}\left(P_{i 0}(t)+\Delta P\right)+C_{t}\left(P_{i 0}^{\prime}(t)+\Delta P\right)\right) \\
+\lambda(t)\left(P_{d}(t)+P_{L 0}(t)+\sum_{i=1}^{I} \delta_{i 0}(t)\left(P_{i}+\Delta P_{i}^{\prime}\right)+\right. \\
\sum_{j=1}^{J} \delta_{j 0}(t) \Delta P_{j}-\sum_{i=1}^{I}\left(P_{i 0}(t)+\Delta P_{i}+P_{i 0}^{\prime}(t)+\Delta P_{i}^{\prime}\right) \\
\left.\quad-\sum_{j=1}^{J}\left(P_{j 0}(t)+\Delta P_{j}\right)\right) \\
+\mu(t)\left(P_{d}(t)+P_{L 0}(t)+\sum_{i=1}^{I} \delta_{i 0}(t)\left(\Delta P+\Delta P^{\prime}\right)\right. \\
\left.\left.\left.\quad+\sum_{j=1}^{J} \delta_{j 0}(t) \Delta P_{j}+R^{t}\right)-\sum_{i=1}^{I} \overline{P_{i \max }(t)}-\sum_{j=1}^{J} \overline{P_{j \max }(t)}\right)\right]
\end{aligned}
$$$$
\text { Where: } \quad \delta_{i 0}(t)=\left.\frac{\partial P_{l}(t)}{\partial\left(P_{i}(t)+P_{i}^{\prime}(t)\right)}\right|_{P_{0}(t)} \quad, \quad \delta_{j 0}(t)=\left.\frac{\partial P_{l}(t)}{\partial P_{j}(t)}\right|_{P_{00}(t)} \quad \text { are }
$$

incremental grid loss of the each power plant.

Constrain $P_{0}(t)$

is: $P_{d}(t)+P_{L 0}(t)-\sum_{i=1}^{I}\left(P_{i 0}(t)+P_{i 0}{ }^{\prime}(t)\right)-\sum_{j=1}^{J} P_{j 0}(t)=0$

At the same time, $\Delta P_{i}+\Delta P_{i}^{\prime}=P_{i}(t)+P_{i}^{\prime}(t)-P_{i 0}(t)-P_{i 0}{ }^{\prime}(t)$,

$$
\Delta P_{j}=P_{j}(t)-P_{j 0}(t)
$$

Using the Equation (5),(6) to (4), can calculate:

$$
L(P, \lambda, \mu)=L_{1}\left(P_{i}, P_{i}^{\prime}, \lambda, \mu\right)+L_{2}\left(P_{j}, \lambda, \mu\right)+M
$$

Where: $\sum_{t=1}^{T} \sum_{i=1}^{I}\left(C_{i}+(\lambda(t)+\mu(t)) \delta_{i 0}(t)-\lambda(t)\right) P_{i}(t)$,

$$
\begin{gathered}
\left.+\left(C_{t}^{\prime}+(\lambda(t)+\mu(t)) \delta_{i 0}(t)-\lambda(t)\right) P_{i}^{\prime}(t)\right) \\
L_{2}\left(P_{j}, \lambda, \mu\right)=\sum_{t=1}^{T} \sum_{j=1}^{J}\left((\lambda(t)+\mu(t)) \delta_{j 0}(t)-\lambda(t)\right) P_{j}(t)
\end{gathered}
$$




$$
\begin{aligned}
& M=\sum_{t=1}^{T}\left[\mu(t)\left(P_{d}(t)+P_{L 0}(t)+R^{t}-\sum_{i=1}^{I} \overline{P_{i \max }(t)}-\sum_{j=1}^{J} \overline{P_{j \max }(t)}\right)\right. \\
& -\sum_{i=1}^{I}\left((\lambda(t)+\mu(t)) \delta_{i 0}(t)-\lambda(t)\right)\left(P_{i 0}(t)+P_{i 0}^{\prime}(t)\right) \\
& \left.-\sum_{j=1}^{J}\left((\lambda(t)+\mu(t)) \delta_{j 0}(t)-\lambda(t)\right) P_{j 0}(t)\right]
\end{aligned}
$$

If $\lambda(t), \mu(t)$ is determination, then, $\mathrm{M}$ as the constant. $L_{1}\left(P_{i}, P_{i}^{\prime}, \lambda, \mu\right)$ only is related with the thermal units power and $L_{2}\left(P_{j}, \lambda, \mu\right)$ only is related with the hydro units power. So, the Equation (7) is decomposed as the single sub optimization problem of thermal units and hydro units.

\section{SUB OPTIMIZATION CALCULATION OF HYDRO UNITS AND THERMAL UNITS}

For solving the sub optimization problem of hydro units, the multi-period multi-unit dynamic problem may be decomposed as the single period optimization unit commitment problem. Then, the single period optimization unit commitment is calculated basing on the incremental rate change method. The calculation speed may be improved greatly with the large-scale multi-period multi-unit commitment problem decomposed as the single period optimization. It is benefit to the online calculation. At the same time, the parameters is corrected appropriately in the calculation proceeding, the calculation accuracy is ensured. Thus, this avoids the difficults of unsuitable the large-scale multi-period multi-unit commitment problem from the equal increment method, no high accuracy results from liner programming, the dimension-disaster from the dynamic programming and long calculation time form the modern artificial intelligence algorithm.

For the thermal units optimization, the method based on coordination efficiency priority, linear programming, and DC optimal power flow are used to solve it[3]. This make the solution process becomes simple and reasonable, easy and reliable. It solves not only the dynamic time-correlation, combinatorial explosion difficulties of thermal optimization, but also the non-linear constraint of power grid. So the calculation time is shortened greatly. It achieves the realtime computing requirements.

\section{Simulation CALCUlation AND CASE ASNALysis}

\section{A. Base data of IEEE-30 bus system}

Using the IEEE-30 bus grid as the case, the grid topological relation and branch parameters is the IEEE-30 bus original parameters. The other parameters are reliable hypothesized from the general power flow calculation of IEEE-30 bus system with the actual operation situation. Assumption the system includes seven thermal units and four hydro units. Some mostly parameters of the units is in the Table.1-3. One day includes 48 periods in the case of optimization calculation. The results of calculation are in Figure.1-3.

\section{B. Result Asnalysis}

Figure. 1 displays the light load periods 3-5 o'clock, CPP (competitive price of each period) is low, the hydro unit output is small, some is 0 . The other high load periods, the hydro units' output is more; the trend is same as the CPP. The goal is realized to use the hydro unit adjusting load spike and coordinate the hydro-thermal dispatching.

Figure. 2 displays the thermal unit total output in each period. Seeing from the calculation results, the big capacity, low contract price and high efficiency thermal unit output is more, the base load unit1-3 output is all. The small capacity, high price and low efficiency unit 6 output small, and the unit 7 output is 0 in each period. The results displays the efficiency priority, phase-out high cost unit rules, it accords with the demand of society and environment development.

Figure. 3 displays the thermal unit competitive output in each period(TUCOP). Seeing from the figure, the TUCOP is up to the unit competitive volumes up limit. The big capacity and high efficiency thermal unit output is more. Because the competitive price is more lower the contract price. This accord with the market rules, and satisfies calculation demand of electricity market. The total contract and competitive purchase cost is 679.11 million $Y$ and 72.52 million $¥$. The total cost is 751.63 million $¥$.

\section{CONCLUSION}

The actual IEEE-30 bus system case proves the dispatching strategies designed may be coordinating the hydro-thermal optimization. This makes full use of hydro output, adjusts the strike price of electricity market in the load strike period. The total cost, the thermal units' market power are reduced. At the same time, the contract volumes protect the thermal unit benefit, the system capacity and operation stability are ensured, the social benefit is improved. The calculation result is satisfied with the system operation constraints, according with the market rules. That proves the method correctly.

\section{REFERENCES}

[1] I.A.Farhat; M.E.El-Hawary. Optimization methods applied for solving the short-term hydrothermal coordination problem[J]. Electric Power Systems Research, 2009,79(9):1308-1320

[2] V. Senthil Kumar; M.R. Mohan. Solution to security constrained unit commitment problem using genetic algorithm[J]. International Journal of Electrical Power \& Energy Systems, 2010, 32(2): 117125

[3] JIANG Dongrong; LIU Xuejun; LI Qunzhan. Economically distributing strategies for daily generation scheduling in a power system under power market environment[J]. Proceedings of the CSEE, 2004, 24(7) : 90-94(in Chinese) 
TABLE I. KIND AND THE UP-DOWN LIMIT OF THE UNITS OUTPUT (UP-DOWN LIMIT OF HYDRO UNIT IS THE WATER COST M3/S)

\begin{tabular}{cccc}
\hline BUS NUMBER & BUS KIND & UP MW & DOWN MW \\
\hline 1 & TU 1 & 150 & 80 \\
2 & TU 2 & 120 & 50 \\
8 & TU 3 & 120 & 50 \\
13 & HU 1 & 45 & 40 \\
14 & TU 4 & 120 & 30 \\
20 & HU 2 & 30 & 30 \\
22 & TU 5 & 80 & 40 \\
23 & TU 6 & 80 & 40 \\
27 & HU 3 & 30 & \\
28 & TU 7 & 80 & 35 \\
30 & HU 4 & WHERE: TU IS THERMAL UNIT, HU IS HYDRO UNIT.
\end{tabular}

TABLE II. THE OTHER RUNNING PARAMETERS OF THERMAL UNIT

\begin{tabular}{|c|c|c|c|c|}
\hline Bus number & Unit name & $\begin{array}{c}\text { Thermal Unit } \\
\text { Contract price } ¥ / \mathrm{MW}\end{array}$ & $\begin{array}{c}\text { Stop-Run } \\
\text { number limit }\end{array}$ & $\begin{array}{l}\text { Stop time } \\
\text { periods limit }\end{array}$ \\
\hline 1 & TU 1 & 264 & 1 & 8 \\
\hline 2 & TU 2 & 268 & 1 & 6 \\
\hline 8 & TU 3 & 272 & 1 & 6 \\
\hline 14 & TU 4 & 300 & 2 & 6 \\
\hline 22 & TU 5 & 312 & 2 & 6 \\
\hline 23 & TU 6 & 360 & 2 & 4 \\
\hline 28 & TU 7 & 400 & 1 & 4 \\
\hline
\end{tabular}

TABLE III. THE OTHER RUNNING PARAMETERS OF HYDRO UNIT

\begin{tabular}{cccccccccc}
\hline $\begin{array}{c}\text { Bus } \\
\text { number }\end{array}$ & $\begin{array}{c}\text { Unit } \\
\text { name }\end{array}$ & $\begin{array}{c}\text { Reservoir } \\
\text { Area } \\
\text { million }_{\mathrm{m}^{2}}\end{array}$ & $\begin{array}{c}\text { Water } \\
\text { Input } \\
\text { Speed } \\
\mathrm{m}^{3} / \mathrm{s}\end{array}$ & $\begin{array}{c}\text { Water } \\
\text { energy } \\
\text { Rate }\end{array}$ & $\begin{array}{c}\text { Total } \\
\text { daily } \\
\text { water } \\
\text { cost m }\end{array}$ & $\begin{array}{c}\text { Start } \\
\text { Water } \\
\text {-level m }\end{array}$ & $\begin{array}{c}\text { Min } \\
\text { Water } \\
\text { mel }\end{array}$ & $\begin{array}{c}\text { Max } \\
\text { water } \\
\text { speed } \\
\mathrm{m}^{3} / \mathrm{s}\end{array}$ \\
\hline 13 & HU 1 & 20 & 0 & 0.98 & 3.5 & 100 & 98 & 45 \\
20 & HU 2 & 12 & 0 & 0.98 & 1.5 & 120 & 117 & 20 & 20 \\
27 & HU 3 & 10 & 0 & 0.98 & 1.4 & 80 & 76 & 20 \\
30 & HU 4 & 13 & 0 & 0.98 & 1.3 & 60 & 56 & 20 \\
\hline
\end{tabular}

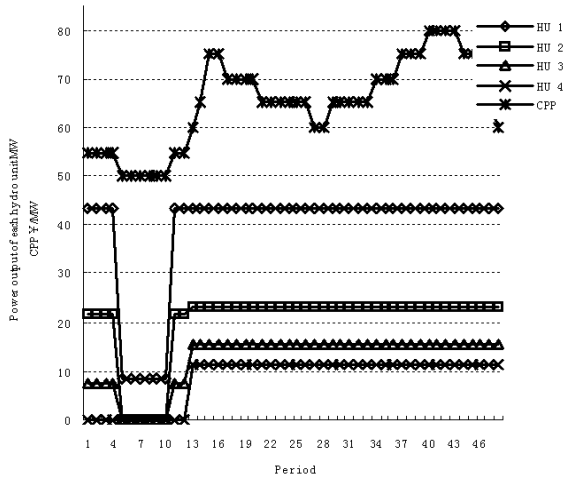

Figure 1.Hydro unit output 


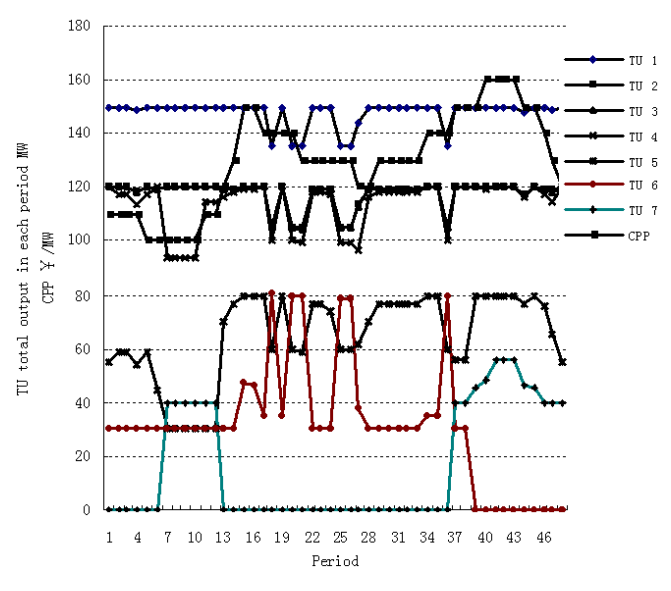

Figure 2. Thermal unit output and CPP

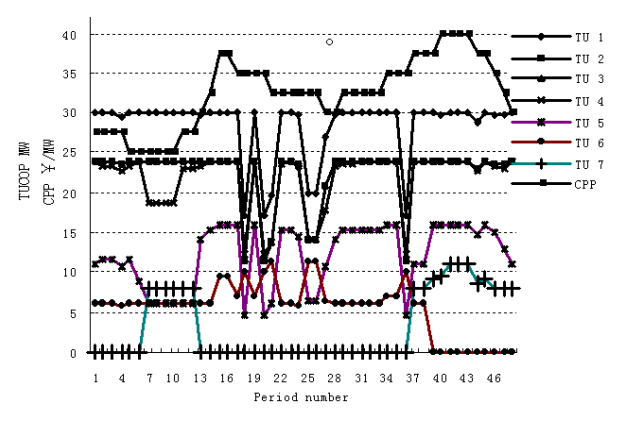

Figure 3. TUCOP in each period 